\title{
Role of ultrasound in diagnosis of fetal congenital abdominal anomalies: One year prospective study
}

\author{
Kaur $\mathbf{N}^{1}$, Pamnani $\mathbf{S}^{2}$, Kaur $\mathbf{B}^{3}$ \\ ${ }^{1}$ Dr. Navkiran Kaur, Professor and Head of Radio-diagnosis Department, GMC Patiala, ${ }^{2}$ Dr. Sangeeta Pamnani, \\ Resident, Radiodiagnosis, GMC Patiala, ${ }^{3}$ Dr. Balwinder Kaur, Associate Professor, Department of Obstetrics \\ and Gyenecology, GMC Patiala, Punjab, India.
}

Address for Correspondence: Dr. Sangeeta Pamnani, Email: drsang.07@gmail.com

\begin{abstract}
Introduction: Congenital anomalies are important cause of perinatal and infant mortality, and are contributor to childhood morbidity. Fetal congenital abdominal anomalies are one of the most common anomalies. Ultrasound screening of fetus helps to identify these anomalies as early as possible in antenatal period and thus provides information for proper decisions during pregnancy. Aim: To find out the incidence of congenital abdominal anomalies affecting fetus and to study the outcome in patients with fetal congenital abdominal anomalies by following them postnatally. Material and Methods: Prospective, Observational and Non-interventional study. Ultrasound screening of 5761 fetuses were performed. Pregnancies, with ultrasound findings of fetal congenital abdominal anomalies with or without other associated anomalies, were followed up. Postnatal confirmation of anomalies were carried out by clinical examination/ imaging procedures / autopsy. Results: Incidence of fetal congenital abdominal anomalies was 5.56 per 1000 births. Among the fetal congenital abdominal anomalies, fetal urinary tract anomalies were the most common with an incidence of 4.69 per 1000 births. Incidence of Omphalocele, Gastroschisis and Jejunoileal atresia were 5.2, 1.7 and 1.7 per 10,000 births respectively. Concordance between antenatal and postnatal diagnosis was $90.63 \%$. Conclusion: Antenatal ultrasound examination should be performed for all pregnant women to diagnose congenital anomalies. Prenatal diagnosis of congenital anomalies provides information for proper decisions during pregnancy, fetal intervention if available and appropriate treatment perinatally, thus improves perinatal and long term outcomes.
\end{abstract}

Keywords: Fetal congenital abdominal anomalies, Fetal urinary tract anomalies, Omphalocele, Gastroschisis.

\section{Introduction}

Advances in medicine have led to decline in diseases like infections and malnutrition, so the congenital malformations have emerged gaining great importance in perinatal mortality [1]. Congenital anomalies account for $8-15 \%$ of perinatal deaths and $13-16 \%$ of neonatal deaths in India [2,3]. The pattern and prevalence of congenital anomalies may vary over time or with geographical location, reflecting a complex interaction of known and unknown genetic and environmental factors including socio-cultural, racial and ethnic variables [4]. Ultrasound is the non-invasive screening modality of choice for the detection of congenital anomalies because of its

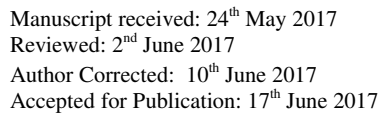

safety, cost effectiveness and detection sensitivity. Incidence of antenatally diagnosed congenital anomalies is increasing as compared to past because of advanced diagnostic facilities and routine antenatal ultrasound examination should be performed for all pregnant women to diagnose these anomalies. Prenatal diagnosis of congenital anomalies provides information for proper decisions during pregnancy, fetal intervention if available and appropriate treatment perinatally (timed delivery in tertiary care centres), thus improves perinatal and long term outcomes [5].

Anterior abdominal wall defects comprising omphalocele, gastroschisis, and bladder exstrophy remain a source of significant morbidity and mortality [6]. While esophageal atresia, duodenal 
atresia, jejunoileal atresia and anorectal atresia are the common gastrointestinal tract anomalies. Urinary tract anomalies account for $33 \%$ of all malformations detected by routine prenatal sonography [7]. Renal agenesis, Renal ectopia, Horseshoe kidney, Multicystic dysplastic kidney, Cystic Renal Dysplasia with Obstruction, Autosomal recessive polycystic kidney disease (ARPKD), Autosomal dominant polycystic kidney disease (ADPKD), Hydronephrosis and fetal megacystis are commonly diagnosed urinary tract anomalies during antenatal period.

Aim of the Study: To find out the incidence of congenital abdominal anomalies affecting fetus and to study the outcome in patients with fetal congenital abdominal anomalies by following them postnatally.

\section{Material and Methods}

This was a hospital based prospective, observational and non-interventional study, conducted in Department of Radio diagnosis in collaboration with Department of Obstetrics and Gynaecology at Rajindra Hospital, Patiala. Study was conducted for a period of one year from $1^{\text {st }}$ Jan 2015 to $31^{\text {st }}$ Dec 2015. Pregnant cases with gestational age $\geq 10$ weeks undergoing routine antenatal screening having congenital abdominal anomalies with or without other associated anomalies were included. Pregnant cases with gestational age $<10$ weeks were excluded. Institutional review board approval for conducting this study was obtained and informed written consent for participation in this study was taken from all patients.

Ultrasound examination was performed transabdominally on 'Philips HD $11 \mathrm{XE}$ ' machine with 2-5 $\mathrm{MHz}$ broadband convex probe. Positive cases were followed to know the ultimate outcome of pregnancy i.e. aborted/ terminated/ delivered. Postnatal confirmation of congenital abdominal anomalies were carried out by clinical examination/ imaging procedures / autopsy. Result were statistically analysed by SPSS software.

\section{Results}

Total 5761 fetuses with gestational age $\geq 10$ weeks were screened by ultrasound. 32 cases of fetal congenital abdominal anomalies with or without other associated anomalies were diagnosed by ultrasound during the one year study period. Incidence of fetal congenital abdominal anomalies was 5.56 per 1000 births. Among the fetal congenital abdominal anomalies, fetal urinary tract anomalies were the most common with an incidence of 4.69 per 1000 births. Incidence of Omphalocele, Gastroschisis and Jejuno-ileal atresia was found to be 5.2, 1.7 and 1.7 per 10,000 births respectively. Among fetal congenital abdominal anomalies, fetal urinary tract anomalies $(84.38 \%)$ were the most common followed by fetal anterior abdominal wall defects $(12.50 \%)$ and fetal GI tract anomaly $(3.13 \%)$.

Table-1: Distribution of different fetal congenital abdominal anomalies detected.

\begin{tabular}{|c|c|c|}
\hline Fetal Congenital Abdominal Anomalies & Number of cases & Percentage \\
\hline Fetal Urinary Tract Anomalies & $\mathbf{2 7}$ & $\mathbf{8 4 . 3 8 \%}$ \\
\hline HDN & 14 & $43.75 \%$ \\
\hline MCDK & 6 & $18.75 \%$ \\
\hline Renal Agenesis & 5 & $15.63 \%$ \\
\hline Polycystic Kidney Disease & 1 & $3.13 \%$ \\
\hline BOO & 1 & $3.13 \%$ \\
\hline Fetal Anterior Abdominal Wall Defects & $\mathbf{1 2 . 5 0 \%}$ \\
\hline Omphalocele & 3 & $9.38 \%$ \\
\hline Gastroschisis & 1 & $3.13 \%$ \\
\hline Fetal GI Tract Anomaly & $\mathbf{4}$ & $\mathbf{3 . 1 3 \%}$ \\
\hline Jejuno-ileal atresia & 1 & $3.13 \%$ \\
\hline Total & $\mathbf{3 2}$ & $\mathbf{1 0 0 . 0 \%}$ \\
\hline
\end{tabular}

Among the fetal urinary tract anomalies, hydronephrosis $(43.75 \%)$ was most common followed by multicystic 


\section{Original Research Article}

dysplastic kidney (18.75\%) and renal agenesis (15.63\%). Among fetal anterior abdominal wall defects, omphalocele $(9.38 \%)$ was 3 times more common than gastroschisis (3.13\%). A single case of jejuno-ileal atresia $(3.13 \%)$ was diagnosed among the fetal GI tract anomalies [Table 1].

The mean POG (Period of Gestation) at the time of antenatal diagnosis of fetal congenital abdominal anomalies was $29.48 \pm 5.53$ weeks. The maternal age ranged from 21 to 37 years, with mean age was $26.34 \pm 4.22$ years. The majority of affected fetuses were male: $21(65.62 \%)$. Females were affected in $11(34.38 \%)$ cases. Majority of cases $(65.63 \%)$ of fetal congenital abdominal anomalies were not associated with any recognizable maternal risk factor. Remaining (34.37\%) cases were associated with known maternal risk factors. Maternal diabetes mellitus was the most common known risk factor associated in $9.38 \%$ cases.

Out of 27 fetuses diagnosed with urinary tract anomalies, 5 (18.52\%) were associated with anomalies of other system. Out of 5, 2 were associated with single umbilical artery, 1 with cleft lip, 1 with VSD and 1 with polydactyly. [Table 2]

Table-2: Fetal urinary tract anomalies associated with anomalies of other system

\begin{tabular}{|c|c|}
\hline Fetal Urinary Tract Anomalies & Associated anomalies of other system \\
\hline MCDK & Cleft lip \\
\hline HDN & Single Umbilical Artery \\
\hline Renal Agenesis & Single Umbilical Artery \\
\hline HDN & VSD (Figure 1) \\
\hline HDN & Polydactyly \\
\hline
\end{tabular}
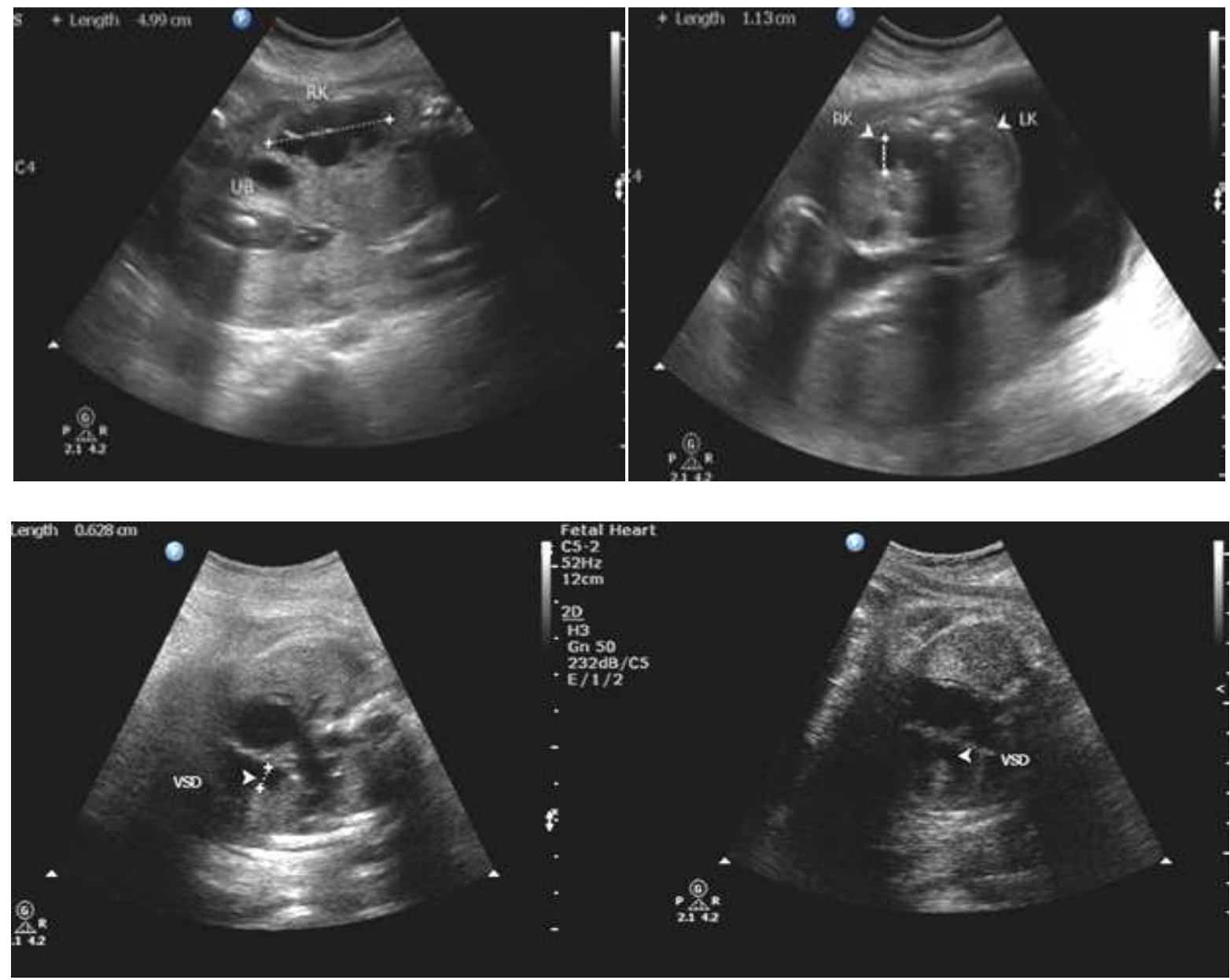

Figure-1A: Antenatal USG shows right kidney hydronephrosis and associated VSD 
Original Research Article

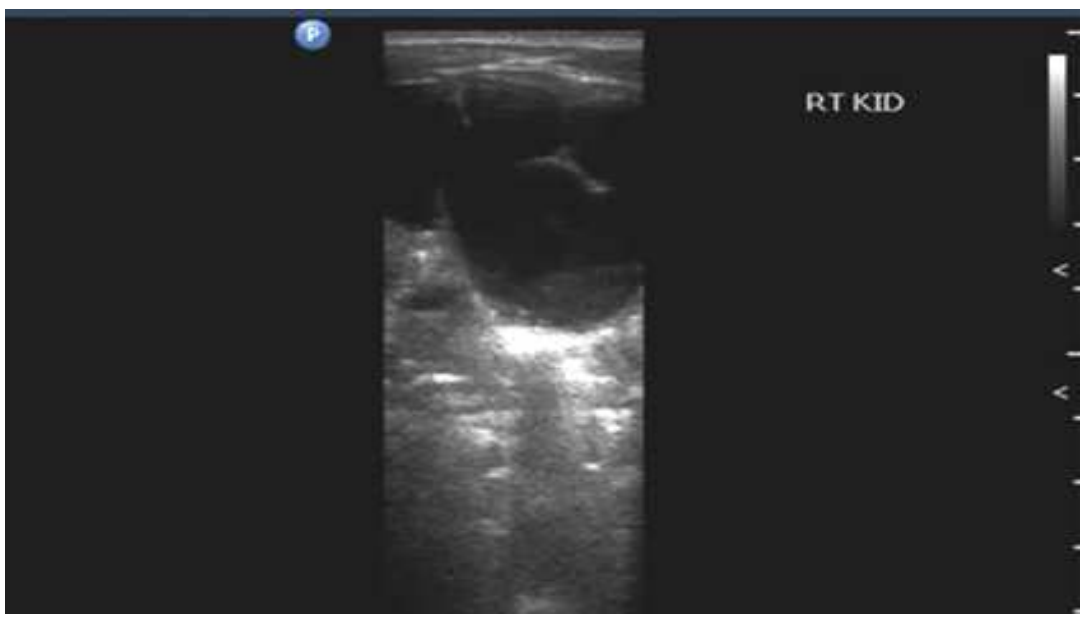

Figure-1B: Postnatal USG confirms right kidney hydronephrosis

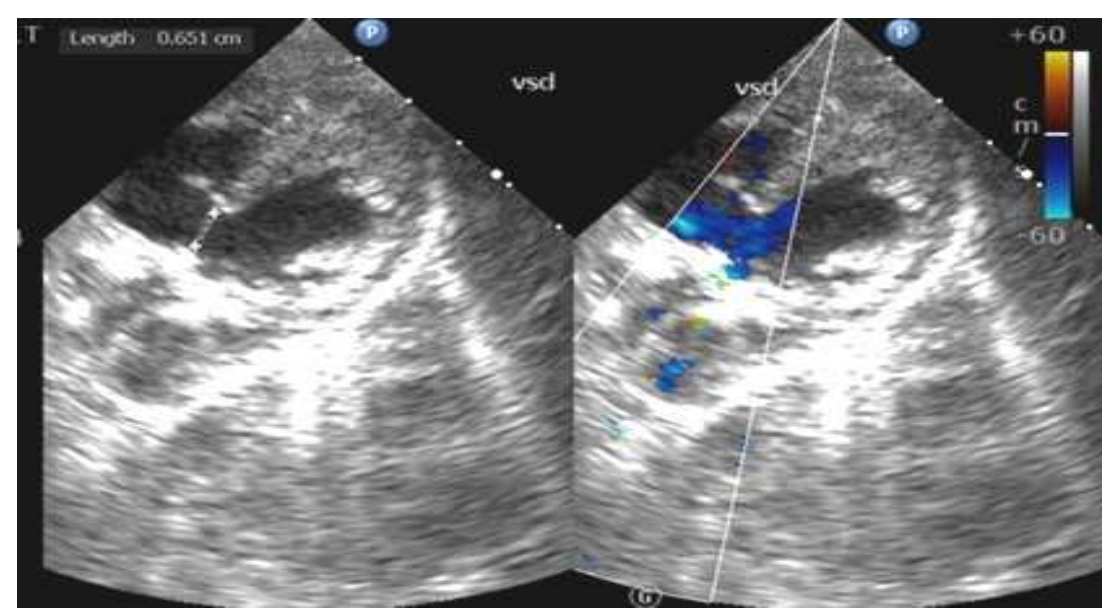

Figure-1C: Postnatal echo of fetus confirms vsd with color flow across defect

2 out of 3 cases of omphalocele were associated with anomalies of other system. One case of omphalocele was associated with hydrocephalus, spinal deformity, cleft lip, club foot and ectopia cordis (Figure-2) and other case with Myelomeningocoele.
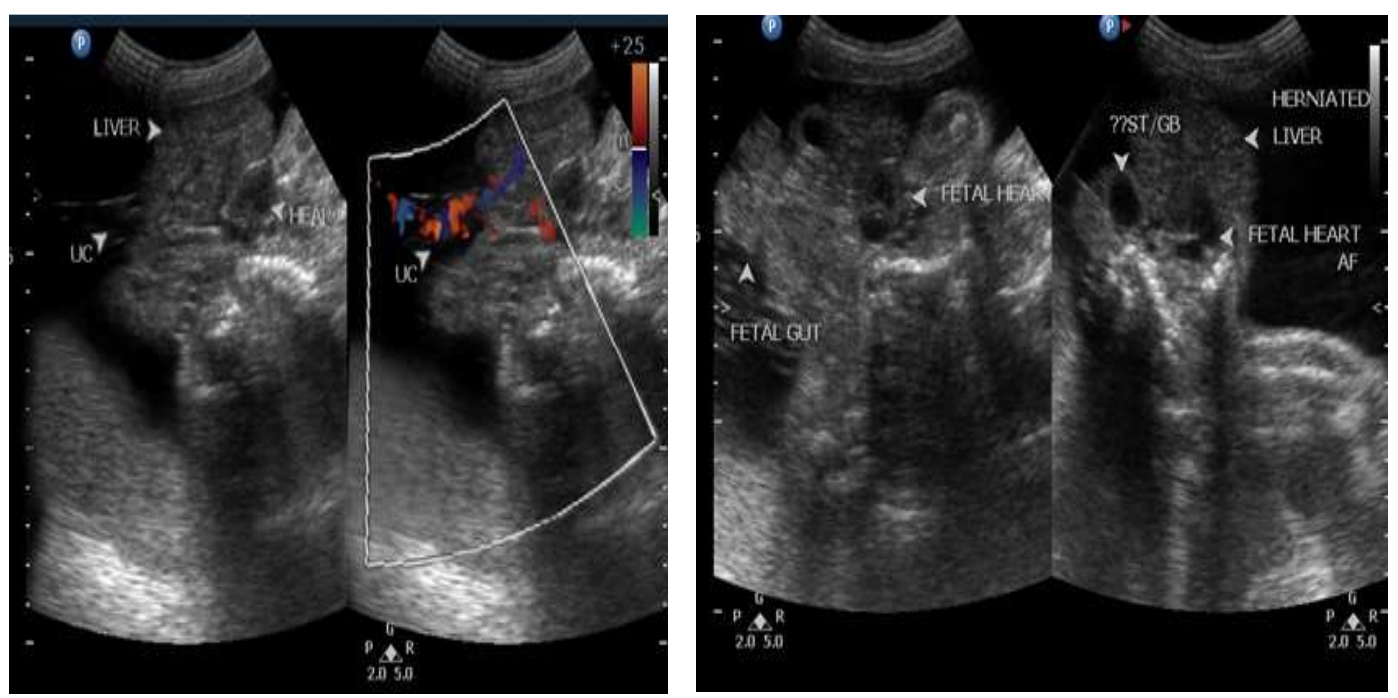

Figure-2A: Antenatal USG shows herniated liver and gut loops out of fetal abdomen at the base of umbilical cord insertion. Ectopia cordis also seen 
Original Research Article
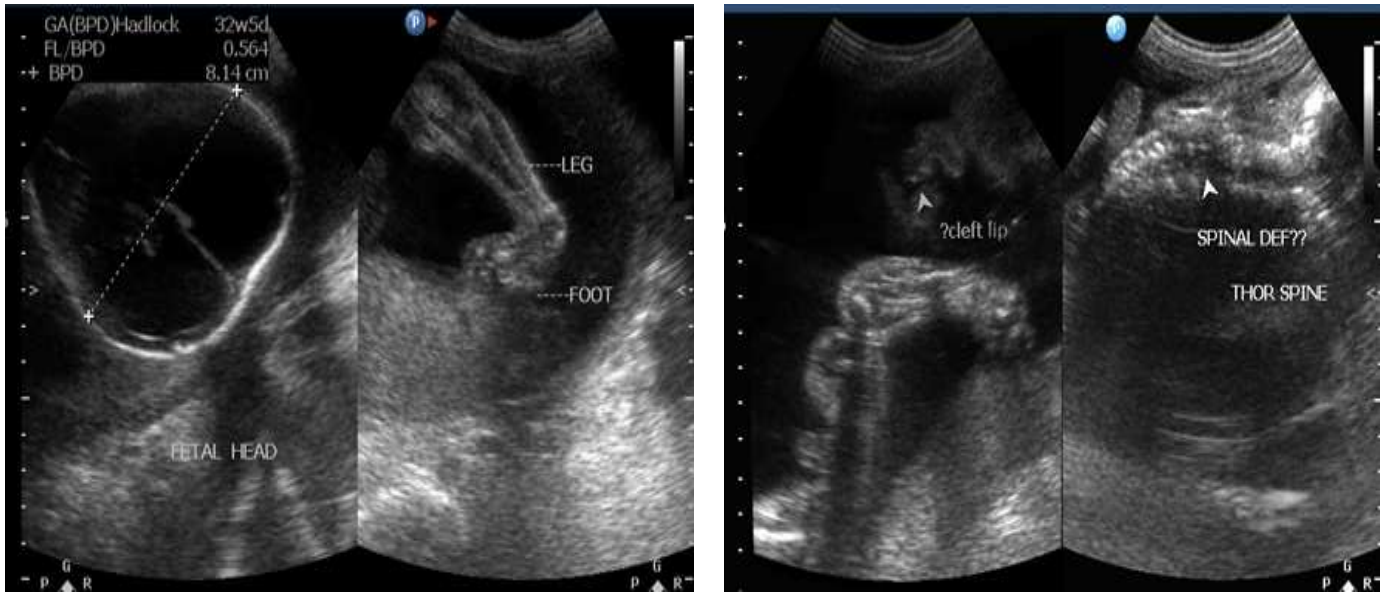

Figure-2B: Antenatal USG shows hydrocephalus, club foot Cleft lip and spinal deformity

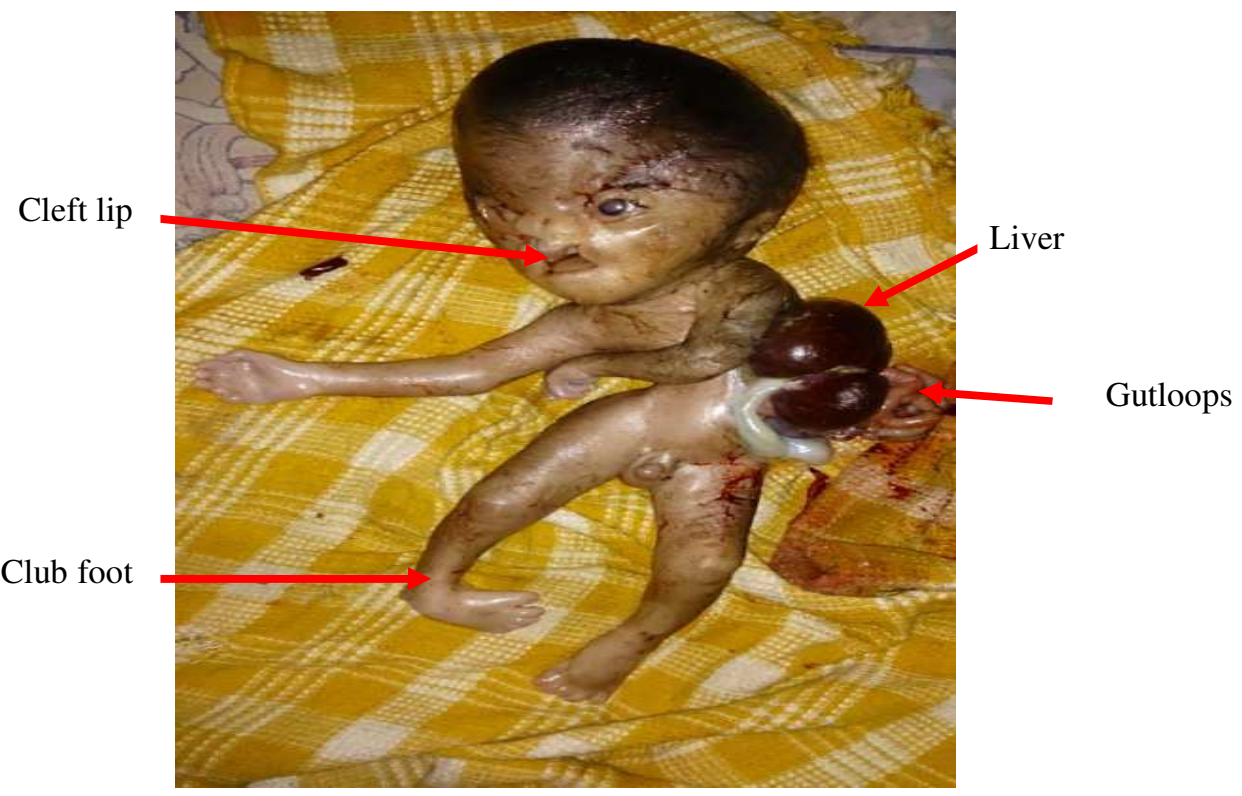

Figure-2C: Abortus shows omphalocele with herniated liver and gut loops; club foot and cleft lip

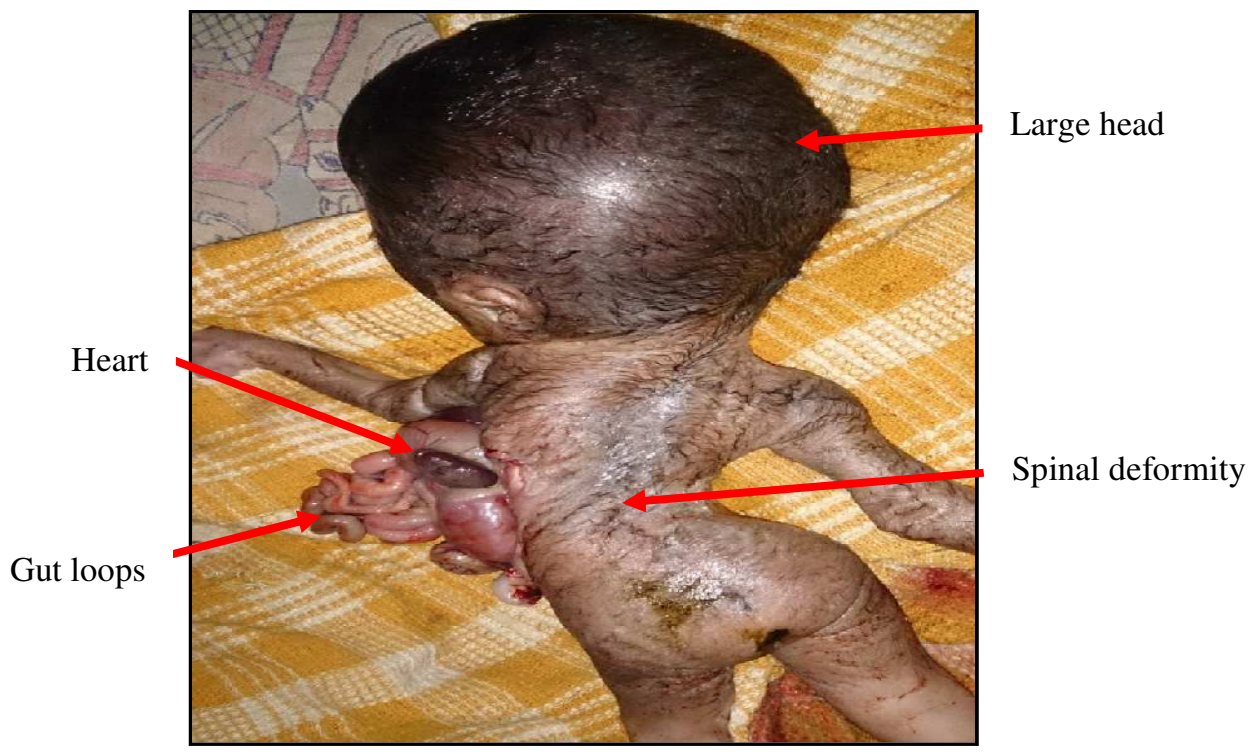

Figure- 2D: Abortus shows ectopia cordis, large head, herniated gut loops and spinal deformity 
Oligohydramnions was seen in $8(29.63 \%)$ out of 27 pregnancies with fetal urinary tract anomalies. Out of 27 cases of fetal urinary tract anomalies, 18 cases $(66.67 \%)$ were delivered as term live baby and 5 cases $(18.52 \%)$ as preterm live baby resulting in total 23 live born babies (85.19\%). 2 cases (7.41\%) underwent MTP and in 2 cases $(7.41 \%)$ intrauterine death was observed. Intrauterine death occurred in fetuses diagnosed to have bilateral multicystic dysplastic kidneys and bladder outlet obstruction respectively. Termination of pregnancies were done in two cases both diagnosed to have bilateral renal agenesis.

Out of 4 cases of fetal anterior abdominal wall defect, intrauterine death was observed in 2 cases, 1 case underwent MTP and 1 case delivered as preterm live baby. A single case of fetal GI tract anomaly (jejuno-ileal atresia) was delivered as term live baby.

Postnatal confirmation of antenatally diagnosed fetal congenital abdominal anomalies was done by clinical examination/ imaging procedures / autopsy.

Agreement between antenatal and postnatal diagnosis was seen in 29 out of 32 cases resulting in concordance found to be $90.63 \%$. Agreement between antenatal and postnatal diagnosis was seen in 24 cases of urinary tract anomalies, 4 cases of anterior abdominal wall defects and in 1 case of GI tract anomaly. In the remaining 3 cases of urinary tract anomalies variations between antenatal and postnatal diagnosis were found.

Normal renal scans were seen postnatally in one infant diagnosed to have right hydronephrotic kidney and in one infant diagnosed to have left renal agenesis antenatally. One infant found to have left hydronephrotic kidney on antenatal scans showed multicystic dysplastic left kidney on postnatal scans.

\section{Discussion}

With improved control of infections and nutritional deficiency diseases, congenital malformations have become important causes of perinatal and neonatal mortality in developing countries like India [4]

Presently Ultrasound is the best screening method for prenatal detection of fetal congenital anomalies because of its safety, availability, accuracy, and cost-effectiveness [5]. Early diagnosis of congenital anomalies provides information to parents so they can make decisions about whether to continue or terminate the pregnancy and what their options are for fetal or postnatal repair.

In the present study, 32 cases of fetal congenital abdominal anomalies were diagnosed out of 5761 cases scanned, resulting an incidence of 5.56 per 1000 births. Among the fetal congenital abdominal anomalies, fetal urinary tract anomalies ( 27 cases) were the most common with an incidence of 4.69 per 1000 births which is comparable to the study done by Saha et al [8], reported the incidence of fetal urinary tract anomalies 4 per 1000 births. In our study, only 4 cases of fetal anterior abdominal wall defects and one case of jejuno-ileal atresia were diagnosed.

Among the fetal urinary tract anomalies, hydronephrosis $(43.75 \%)$ was the most common followed by multicystic dysplastic kidney (18.75\%) and renal agenesis (15.63\%). This result of our study is consistent with those of previous studies done by, Kim and Song et al [9], Vega et al [10], Bondagji et al [11] and Kumar et al [12].

Table-3: Distribution of fetal urinary tract anomalies

\begin{tabular}{|c|c|c|c|}
\hline Author and year of study & Hydronephrosis & MCDK & Renal agenesis \\
\hline Kim and Song [9] & $77 \%$ & $10.4 \%$ & $4.2 \%$ \\
\hline De La Vega et al [10] & $54.7 \%$ & $17.9 \%$ & $12.8 \%$ \\
\hline Bondagji [11] & $51.1 \%$ & $12.8 \%$ & $8.5 \%$ \\
\hline Kumar et al [12] & $44.9 \%$ & $26.4 \%$ & $8 \%$ \\
\hline Present Study & $43.75 \%$ & $18.75 \%$ & $15.63 \%$ \\
\hline
\end{tabular}


Early detection of congenital anomalies provides information regarding the important decision during pregnancy whether to terminate or continue pregnancy, any fetal intervention if available and proper postnatal management of infant. In the present study average gestational age for ultrasound diagnosis of congenital abdominal anomalies was $29.48 \pm 5.53$ weeks. Although ultrasound imaging is highly sensitive for prenatal diagnosis of congenital abdominal anomalies, but diagnosis was not possible before 20 weeks in $90.6 \%$ cases. Major reasons for late diagnosis were either USG performed too early in pregnancy or late referral of cases to the hospital.

Agreement between antenatal and postnatal diagnosis was seen in 29 out of 32 cases resulting in concordance found to be $90.63 \%$. Agreement between antenatal and postnatal diagnosis was seen in 24 cases of urinary tract anomalies, 4 cases of anterior abdominal wall defects and in one case of GI tract anomaly. The concordance between antenatal and postnatal diagnosis of our study is almost similar to study by Bondagji [11] and is comparable to other studies by Sanghvi et al [13], Brunisholz et al [14] and Policiano et al [15]. In contrast, the concordance of our study is much higher than studies by Helin and Persson [16] and Barakat et al [17] [Table 4].

Table-4: Concordance between antenatal and postnatal diagnosis.

\begin{tabular}{|c|c|}
\hline Author and year of study & Percentage \\
\hline Helin and Persson [16] & $65 \%$ \\
\hline Barakat et al [17] & $68 \%$ \\
\hline Sanghviet al [13] & $81.5 \%$ \\
\hline Brunisholzet al [14] & $86 \%$ \\
\hline Policiano et al [15] & $88.8 \%$ \\
\hline Bondagji [11] & $90.1 \%$ \\
\hline Present Study & $90.63 \%$ \\
\hline
\end{tabular}

With time frame, ultrasound is becoming more accurate because of increasing experience of radiologists day by day. It is evident in literature also as shown in table above.

Limitation of Study-In our study, only 4 cases of fetal anterior abdominal wall defects and 1 case of fetal GI tract anomaly were diagnosed because of limited time duration of one year. So, it is not possible to discuss the parameters of these anomalies in detail because literatures about these anomalies are of longer duration with good number of cases available

Parameters eg sensitivity, specificity, positive predictive value, negative predictive value couldn't be assessed as only positive cases were followed postnatally. Single centre study, although highest burden of region, still can't be reflect whole region.

\section{Conclusion}

Incidence of antenatally diagnosed congenital anomalies is increasing as compared to past because of advanced diagnostic facilities and better-trained radiologists. Fetal congenital anomalies are a major cause of perinatal and infant mortality, so routine antenatal ultrasound examination should be performed for all pregnant women to diagnose these anomalies.

Funding: Nil, Conflict of interest: None

Permission of IRB: Not required

\section{References}

1. Patel ZM, Adhia RA. Birth defects surveillance study. Indian J Pediatr. 2005 Jun;72(6):489-91.
2. Bhat BV, Ravikumara M. Perinatal mortality in India-Need for introspection. Indian J Matern Child Health. 1996; 7:31-3.

3.Agarwal SS, Singh U, Singh PS, Singh SS, Das V, Sharma A, Mehra P, Chandravati, Malik GK, Misra PK. Prevalence \& spectrum of congenital malformations in a prospective study at a teaching hospital. Indian J Med Res. 1991 Dec;94:413-9.

4. Sarkar S, Patra C, Dasgupta MK, Nayek K, Karmakar PR. Prevalence of congenital anomalies in neonates and associated risk factors in a tertiary care hospital in eastern India. J Clin Neonatol. 2013 Jul;2(3):131-4. doi: 10.4103/2249-4847.119998. 


\section{Original Research Article}

5. Wilson RD: SOGC genetics committee; special contributor. Prenatal screening, diagnosis, and pregnancy management of fetal neural tube defects. J Obstet Gynaecol Can. 2014 Oct;36(10):927-939. doi: 10.1016/S1701-2163(15)30444-8.

6. Grigore M, Iliev G, Gafiteanu D, Cojocaru C. The fetal abdominal wall defects using $2 \mathrm{D}$ and $3 \mathrm{D}$ ultrasound. Pictorial essay. Med Ultrason 2012;14 (4): 341-47.

7. Grandjean H, Larroque D, Levi S. The performance of routine ultrasonographic screening of pregnancies in the Eurofetus Study. Am J Obstet Gynecol. 1999 Aug;181(2):446-54.

8. Saha A, Batra P, Chaturvedi P, Mehra B, Tayade A. Antenatal Detection of Renal Malformations. Indian Pediatrics2008;46:346-48.

9. Kim EK, Song TB. A study on fetal urinary tract anomaly: antenatal ultrasonographic diagnosis and postnatal follow-up. J Obstet Gynaecol Res. 1996 Dec;22(6):569-73.

10. De La Vega A, Torres E. Prenatal diagnosis of renal disease. P R Health Sci J. 2005 Jun;24(2): $141-4$.

11. Bondagji NS. Antenatal diagnosis, prevalence and outcome of congenital anomalies of the kidney and urinary tract in Saudi Arabia. Urology Annals. 2014 Jan-Mar; 6(1):36-40. doi:10.4103/0974-7796. 127021 .
12. Kumar M, Thakur S, Puri A, Shukla S, Sharma S, Perumal V, Chawla R, Gupta U. Fetal renal anomaly: factors that predict survival. J Pediatr Urol. 2014 Dec;10(6):1001-7. doi: 10.1016/j.jpurol. 2014.11.007. Epub 2014 Nov 12.

13. Sanghvi KP, Merchant RH, Gondhalekar A, Lulla CP, Mehta AA, Mehta KP. Antenatal diagnosis of congenital renal malformations using ultrasound. J Trop Pediatr. 1998 Aug; 44 (4): 235-40.

14. Brunisholz Y, Vial Y, Brignon CM, Meyrat BJ, Frey P, Hohlfeld P. Prenatal diagnosis of urinary malformations: results in a series of 93 consecutive cases. Swiss Med Wkly. 2001 Feb 24; 131(7-8): 95-8.

15. Policiano C, Djokovic D, Carvalho R, Monteiro C, Melo MA, Graça LM. Ultrasound antenatal detection of urinary tract anomalies in the last decade: outcome and prognosis. J Matern Fetal Neonatal Med. 2015 May; 28 (8):959-63. doi: 10.3109/14767058.2014.939065.

16. Helin I, Persson PH. Prenatal diagnosis of urinary tract abnormalities by ultrasound. Pediatrics. 1986 Nov;78(5):879-83.

17. Barakat AJ, Butler MG, Cobb CG, Coursey JW, Shah D. Reliability of ultrasound in the prenatal diagnosis of urinary tract abnormalities. Pediatr Nephrol. 1991 Jan;5(1):12-4.

\section{How to cite this article?}

Kaur N, Pamnani S, Kaur B. Role of ultrasound in diagnosis of fetal congenital abdominal anomalies: One year prospective study. Int J Med Res Rev 2017;5(07):649-656. doi:10.17511/ijmrr. 2017.i07.02. 